\title{
STAMBPL1 knockdown has antitumour effects on gastric cancer biological activities
}

\author{
DA-JUN YU, JUN QIAN, XIN JIN, JING LI, CHEN-XU GUO and XI-CHENG YUE
}

Department of Surgical Oncology, The First Affiliated Hospital of Bengbu Medical College, Bengbu, Anhui 233000, P.R. China

Received August 10, 2018; Accepted May 22, 2019

DOI: $10.3892 / \mathrm{ol} .2019 .10789$

\begin{abstract}
The present study aimed to investigate the effects and mechanisms of STAM binding protein-like 1 (STAMBPL1) knockdown in the suppression of gastric cancer activities. Pathological data and STAMBPL1 protein expression were analysed in 36 patients with gastric cancer, including 24 stage I-II and 12 stage III-IV patients, by haematoxylin and eosin staining and immunohistochemistry. In vitro cell experiments were performed to measure AGS cell proliferation, apoptosis, invasion and migration by MTT, Celigo cell count, flow cytometry, Transwell and wound healing assays following STAMBPL1 knockdown. The relative protein expression levels were evaluated by western blotting. When compared with the adjacent normal tissues, STAMBPL1 protein expression in the gastric cancer tissues with increasing stages was significantly upregulated $(\mathrm{P}<0.01$ or $\mathrm{P}<0.001)$. STAMBPL1 gene expression was not identified to be significantly different between AGS and MGC80-3 gastric cancer cells $(\mathrm{P}>0.05)$. Following STAMBPL1 knockdown by short hairpin RNA (sh)STAMBPL1, cell proliferation was significantly suppressed, the cell apoptosis rate was significantly upregulated, and the numbers of invasive AGS cells and the AGS wound healing rate were significantly decreased $(\mathrm{P}<0.01$ and $\mathrm{P}<0.001$, respectively), compared with those in the shControl group. Additionally, STAMBPL1 and NF- $\kappa$ B protein expression levels were significantly downregulated in the shSTAMBPL1 group $(\mathrm{P}<0.001$, respectively). STAMBPL1 may be oncogenic in gastric cancer, and STAMBPL1 knockdown may suppress gastric cancer development.
\end{abstract}

\section{Introduction}

Gastric cancer was one of the four most common malignancies and the third leading cause of cancer-associated mortality

Correspondence to: Dr Jun Qian, Department of Surgical Oncology, The First Affiliated Hospital of Bengbu Medical College, 287 Chang Huai Road, Bengbu, Anhui 233000, P.R. China E-mail: qianjun180522@163.com

Key words: STAM binding protein-like 1, NF-кB, proliferation, apoptosis, invasion, migration in the world in $2014(1,2)$. Although the incidence of gastric cancer has decreased in recent years $(1,2)$, the prognosis of patients remains unsatisfactory due to the lack of effective early detection methods and efficient prognostic markers. In the early stages of gastric cancer, patients experience no specific symptoms, and the majority of patients with gastric cancer are diagnosed at advanced stages, thereby missing the optimal treatment time and, subsequently, resulting in a 5 year survival rate of $<20 \%$ (3). Therefore, the development of novel molecular markers and therapeutic targets for the treatment of gastric cancer is essential.

The results of molecular genetics studies demonstrated that gastric cancer is a malignant tumour, and that gastric cancer occurrence and development is a multi-stage process, with multiple genes and multiple factors involved in a complex process; these genes include oncogenes, tumour suppressor genes and DNA mismatch repair genes $(4,5)$. STAM binding protein-like 1 (STAMBPL1) is a key member of the COP9 signalosome subunit 5/serine protease 27 /proteasome $26 \mathrm{~S}$ subunit non-ATPase 7 (JAMM) family, and a previous study reported that STAMBPL1 was closely associated with tumour development (5). A number of studies reported that STAMBPL1 (also known as AMSHLP) has a positive effect on NF- $\kappa$ B activation, and that it is required for optimal Tax-induced activation of canonical and noncanonical $\mathrm{NF}-\kappa \mathrm{B}$ pathways which are the key component of inflammation development $(6,7)$. However, the effects and mechanism of STAMBPL1 remain unclear. In the present study, STAMBPL1 expression in gastric cancer tissues at different stages was evaluated, and the association between STAMBPL1 protein expression and gastric cancer stages in clinical settings was analysed. Furthermore, the present study demonstrated how STAMBPL1 knockdown affected the biological activities of AGS gastric cancer cells, including proliferation, apoptosis, invasion and migration, as revealed by experiments investigating the $\mathrm{NF}-\kappa \mathrm{B}$ pathway in vitro.

\section{Materials and methods}

Clinical data and samples. Adjacent normal (5 cm away from cancer tissue) and gastric cancer tissues were collected from patients with gastric cancer $(n=36)$ who were treated at The First Affiliated Hospital of Bengbu Medical College between December 2016 and November 2017. The tissues were collected from female $(n=16)$ and male $(n=20)$ patients aged between 30 
and 52 years (mean age, $45 \pm 4.5$ years). The subjects included 24 stage I-II and 12 stage III-IV (8) patients with gastric cancer. All patients were treated for the first time and none of the patients received treatment prior to radical surgery. The adjacent normal and cancer tissues were fixed by $10 \%$ formaldehyde at room temperature for $\geq 24 \mathrm{~h}$. The present study was approved by the Ethics Committee of The First Affiliated Hospital of Bengbu Medical College. All patients provided written informed consent. Following surgery, the tissues were quickly stored in $10 \%$ formaldehyde for fixation until further use.

Haematoxylin and eosin $(H \& E)$ staining. The tissues were fixed in $10 \%$ formaldehyde at room temperature and embedded in paraffin. The wax blocks were sliced into sections of $4 \mu \mathrm{m}$ thickness. The sections of different tissues were stained by $H \& E$ at room temperature to $6 \mathrm{~h}$, and were subjected to pathological classification by TNM staging (8). The sections were observed under a light microscope. No cancer cells were detected in the adjacent normal tissues.

Immunohistochemical (IHC) staining. The tissues were fixed in $10 \%$ formaldehyde at room temperature and embedded in paraffin. The paraffin blocks were sliced into $5 \mu \mathrm{m}$ sections. The sections were incubated at $60^{\circ} \mathrm{C}$ in an oven overnight, dewaxed using a gradient alcohol series (100, 95 and 80\%) and endogenous peroxidase activity was blocked using $3 \%$ $\mathrm{H}_{2} \mathrm{O}_{2}$ at room temperature for $2 \mathrm{~h}$. The remaining steps of IHC staining were performed according to the manufacturer's instructions of the IHC kit (Wuhan Boster Biological Technology, Ltd.). The primary antibody against STAMBPL1 (1:500; cat. no. ab229144; Abcam) was added and incubated at $4^{\circ} \mathrm{C}$ overnight. Following washing with PBS at room temperature, secondary rabbit immunoglobulin $\mathrm{G}$ antibody $(1: 5,000$; cat. no. ab205718; Abcam) was added for $1 \mathrm{~h}$ at room temperature. Subsequently, the sections were observed under a light microscope, and the images were analysed using Image-Pro Plus version 6.0 image analysis software (Version X; Media Cybernetics, Inc.) to measure the STAMBPL1 protein expression in different tissues.

Cell lines and cell culture. Gastric cancer cell lines (AGS and MGC80-3) were purchased from Nanjing KeyGen Biotech Co., Ltd. RPMI 1640 medium (Abcam) containing 10\% FBS (Abcam) and $100 \mathrm{U} / \mathrm{ml}$ penicillin and $100 \mu \mathrm{g} / \mathrm{ml}$ streptomycin (Invitrogen; Thermo Fisher Scientific, Inc.) was used to cultivate gastric cancer cell lines at $37^{\circ} \mathrm{C}$ with $5 \% \mathrm{CO}_{2}$.

Reverse transcription-quantitative PCR (RT- $q P C R)$ assay. The AGS and MGC80-3 cells were collated, and total RNA was extracted using TRIzol kits (Takara Bio, Inc.). GoScript ${ }^{\mathrm{TM}}$ Reverse Transcription System (Promega Corporation) was used for RT of $2 \mu \mathrm{g}$ total RNA to cDNA. The reaction parameters were as follows: $37^{\circ} \mathrm{C}$ for $10 \mathrm{~min}, 42^{\circ} \mathrm{C}$ for $45 \mathrm{~min}$ and $70^{\circ} \mathrm{C}$ for $5 \mathrm{~min}$, followed by cooling on ice for $5 \mathrm{~min}$. Subsequently, $4 \mu \mathrm{l}$ GoScript $^{\mathrm{TM}} 5 \mathrm{X}$ reaction buffer, $1.7 \mu \mathrm{l} \mathrm{MgCl}_{2}$ (final concentration $2 \mathrm{mM}$ ), $1 \mu \mathrm{l} 0.5 \mathrm{mM}$ dNTPs, $0.3 \mu \mathrm{l}$ ribonuclease inhibitor $(20 \mathrm{U}), 1 \mu \mathrm{l}$ reverse transcriptase and ddH2O to a total of $15 \mu \mathrm{l}$ was added. Following mixing, the samples were incubated at $42^{\circ} \mathrm{C}$ for $60 \mathrm{~min}$ and inactivated at $70^{\circ} \mathrm{C}$ for $15 \mathrm{~min}$. RT-qPCR was performed using SYBR ${ }^{\circledR}$ Green Master Mix (Promega
Corporation). The $\mathrm{qPCR}$ was performed in a total volume of $10 \mu \mathrm{l}$ and included the following: $5 \mu \mathrm{l}$ GoTaq $2 \mathrm{X}$ Master Mix, $0.5 \mu \mathrm{l}$ forward primer $(10 \mu \mathrm{M}), 0.5 \mu \mathrm{l}$ reverse primer $(10 \mu \mathrm{M})$, $2 \mu \mathrm{l}$ cDNA (diluted 10-fold) and $2 \mu \mathrm{l} \mathrm{ddH}_{2} \mathrm{O}$. The primers were purchased from Nanjing KeyGen Biotech Co., Ltd. The sequences of primers used were as follows: STAMBPL1 forward 5'-AGGCAGAAAGGAAGCGGATTG-3' and reverse, 5'-TTGCTGACTTCGCATTTGACC-3'; and GAPDH (reference gene) forward, 5'-TGACTTCAACAGCGACACCCA-3' and reverse 5'-CACCCTGTTGCTGTAGCCAAA-3'. The thermocycling conditions were as follows: Pre-denaturation at $94^{\circ} \mathrm{C}$ for $2 \mathrm{~min}$, followed by 35 cycles of $94^{\circ} \mathrm{C}$ for $45 \mathrm{sec}$ and $55^{\circ} \mathrm{C}$ for $60 \mathrm{sec}$ and a final extension at $65^{\circ} \mathrm{C}$ for $20 \mathrm{sec}$. The relative expression of the gene was calculated using the $2^{-\Delta \Delta C q}$ (9) method.

Cell grouping and transfection. AGS cells were assigned to the short hairpin RNA (sh)Ctrl group, which was transfected with empty vector, and the shSTAMBPL1 group, which was transfected with $2 \mathrm{ng} / \mathrm{ml}$ shSTAMBPL1 (Shanghai GeneChem Co., Ltd.) by Lipofectamine ${ }^{\circledR} 2000$ (Invitrogen; Thermo Fisher Scientific, Inc.) according to the manufacturer's protocol to knockdown STAMBPL1. At $48 \mathrm{~h}$, the cells were collected for use in further experiments.

Celigo cell count assay. Logarithmic growth period cells of different groups were collected and digested using $0.05 \%$ pancreatic enzyme to suspend the AGS cells in RPMI 1640 medium, followed by cell counting. AGS cells (100 $\mu \mathrm{l}$; $1 \times 10^{6}$ cells $/ \mathrm{ml}$ ) were added to each well of a 6-well plate and cultured at $37^{\circ} \mathrm{C}$ with $5 \% \mathrm{CO}_{2}$. Starting the next day, the Celigo assay was performed every day for 5 consecutive days.

MTT assay. AGS cell proliferation was measured using an MTT assay kit (Beijing Dingguo Changsheng Biotechnology Co., Ltd.). A total of $2 \times 10^{3}$ cells were added to each well of a 96-well plate. The cells were allowed to adhere and $20 \mu \mathrm{l}$ MTT solution $(5 \mathrm{mg} / \mathrm{ml})$ was added at different time points (days 1 , 2, 3, 4 and 5) and incubated for $4 \mathrm{~h}$ at room temperature. Subsequently, $100 \mu 1$ DMSO was added to the wells to stop the reaction. Cell proliferation was finally measured for different cell groups at different time points at $490 \mathrm{~nm}$.

Cell cloning test. The logarithmic AGS cells of the shCtrl and shSTAMBPL1 groups were collected and suspended in the medium. The cells were inoculated into a 6 -well plate at a density of 1,000 cells/well. Following inoculation, the cells of different groups were continually cultured for 14 days at room temperature. Subsequently, they were washed by PBS, followed by the addition of $1 \mathrm{ml} 4 \%$ paraformaldehyde at room temperature to a final concentration of $2 \%$ to fix the AGS cells for $45 \mathrm{~min}$ at room temperature and washing by PBS. Next, $1,000 \mu \mathrm{l}$ of $4 \%$ crystal violet dye was added to the reaction mix for $15 \mathrm{~min}$ at room temperature. $\mathrm{ddH}_{2} \mathrm{O}$ was used to wash the cells three times, followed by the counting of the cloned cell numbers and capturing of images under a light microscope at x200 magnification.

Cell apoptosis Annexin V-allophycocyanin (APC) assay. AGS cell apoptosis rates of the shCtrl and shSTAMBPL1 
groups were measured using an Flow Cytometry apoptosis kit (cat. no. 88-8007; eBioscience; Thermo Fisher Scientific, Inc.) according to the manufacturer's instructions. In brief, the cells of the experimental groups were collected and centrifuged for $5 \mathrm{~min}$ at $1,300 \times \mathrm{g}$ at $4^{\circ} \mathrm{C}$, the supernatant was removed, and pre-cooled D-Hanks ( $\mathrm{pH} 7.2-7.4$ ) was used to wash the cells at $4^{\circ} \mathrm{C}$. Binding buffer (1X) was used to wash the cells, followed by centrifugation for $3 \mathrm{~min}$ at $1,300 \mathrm{x}$ at $4^{\circ} \mathrm{C}$ to remove the supernatant. Then, the cells were collected, and $200 \mu 11 \mathrm{X}$ Binding Buffer was added to prepare the suspension. Subsequently, $10 \mu \mathrm{l}$ Annexin V-APC was added for staining and allowed to react for $15 \mathrm{~min}$ in the dark at room temperature. Subsequently, cell apoptosis was measured by flow cytometry analysis (FACScalibur; BD Biosciences).

Transwell assay. Matrigel was diluted with fresh medium with $10 \% \mathrm{FBS}$ at a $1: 6$ ratio (by volume) after refrigerating at $4^{\circ} \mathrm{C}$ overnight, and the Transwell insert was placed in a 24-well plate. Subsequently, $50 \mu 1$ Matrigel was added and allowed to dry prior to further use. The cells were digested by adding trypsin to the single cell suspension, and the cell density was adjusted with $10 \%$ FBS. To each well, $1 \times 10^{5}$ cells in $600 \mu 1$ RPMI 1640 medium were added to the upper chamber, and RPMI 1640 medium with 10\% FBS was added to the lower chamber, followed by incubation for $24 \mathrm{~h}$ at room temperature. Subsequently, the Transwell chambers were removed and the culture medium was collected, washed with PBS three times, fixed with $95 \%$ ethanol and stained with $0.5 \%$ crystal violet for $10 \mathrm{~min}$ at room temperature., with a final washing step of washing with PBS three times. Using a cotton swab, the cells were gently wiped off the membrane of the upper chamber, and five fields were randomly selected to count the numbers of cells under a light microscope.

Wound healing assay. AGS cells of the shCtrl and shSTAMBPL1 groups were collected, the medium of the 6-well plate was removed and the cells were washed three times with PBS. A $200-\mu 1$ pipette tip was used to draw a straight line across the centre of the plate along the longitudinal axis, followed by washing twice with PBS and the addition of medium to continue culturing. After 0, 24 and $48 \mathrm{~h}$, five fields were randomly selected to count the number of cells that had migrated into the wound area under an inverted light microscope and images were captured. The experiment was repeated three times.

Western blotting (WB) assay. The AGS cells of shCtrl and shSTAMBPL1 groups were collected, $200 \mu \mathrm{l}$ Cell Lysis Buffer (cat. no. 9803; Cell Signaling Technology, Inc.) was added to extract total protein, and the samples were placed in an ice bath for $20 \mathrm{~min}$, followed by centrifugation at $12,000 \mathrm{x} \mathrm{g}$ for $30 \mathrm{~min}$ at $4^{\circ} \mathrm{C}$; subsequently, the supernatant was removed. The bicinchoninic acid assay method was used to measure the protein concentration. Proteins were separated using $10 \%$ SDS-PAGE with $25 \mu \mathrm{g}$ protein per lane, and the proteins were transferred onto polyvinylidene difluoride membranes. The membranes were blocked with 5\% skimmed milk for $2 \mathrm{~h}$ at room temperature. STAMBPL1 (1:500; cat. no. ab205718;

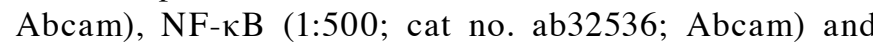
GAPDH (1:1,000; cat no. ab181602; Abcam) antibodies were added and incubated overnight at $4^{\circ} \mathrm{C}$. Then, the membrane was washed three times with PBS for $5 \mathrm{~min}$ and incubated with a horseradish peroxidase-conjugated anti-rabbit IgG secondary antibody (dilution, 1:1,000; cat. no. MBS435036; MyBioSource, Inc.) at room temperature for $2 \mathrm{~h}$. Following washing with PBS, ECL (cat. no. P0018; Beyotime Institute of Biotechnology) was added and the membrane was placed in the Gel Imaging system to develop. The ratio of the target stripe grey value to the internal reference GAPDH grey scale value represented the relative expression amount of each target protein. Quantity one version 4.62 software (Bio-Rad Laboratories, Inc.) was used for analysis.

Statistical analysis. The clinical and experimental data were analysed by SPSS version 22.0 software (IBM Corp.). The data are expressed as the mean \pm standard deviation, and the differences among three or more groups were analysed by one-way ANOVA followed by a post hoc least significant difference-t test. Student's t-test was used to analyse the differences between two groups. $\mathrm{P}<0.05$ was considered to indicate a statistically significant difference. All experiments were repeated 3 times.

\section{Results}

Clinical data and analysis. H\&E staining revealed infiltration of the gastric cancer cells compared with the adjacent normal tissues and this was upregulated with increasing disease stage (Fig. 1A). To evaluate STAMBPL1 protein expression in different tissues, STAMBPL1 expression was measured by IHC staining in adjacent normal, stage I-II and stage III-IV gastric cancer tissues. The present study demonstrated that STAMBPL1 protein expression was significantly upregulated in stage I-II and stage III-IV gastric cancer tissues compared with in the adjacent normal tissues $(\mathrm{P}<0.01$ and $\mathrm{P}<0.001$, respectively; Fig. 1B).

STAMBPL1 expression and transfection. No significant differences were identified among the AGS and MGC80-3 cells in terms of STAMBPL1 gene expression (Fig. 2A). The STAMBPL1 gene expression in AGS was higher compared with that in MGC80-3 cells; therefore, the AGS cell line was selected as a representative gastric cancer cell line.

For shCtrl and shSTAMBPL1 transfection, the efficiency of transfection reached $>80 \%$ and the cell state was normal (Fig. 2B). Following transfection, STAMBPL1 gene expression in the shSTAMBPL1 group was significantly decreased compared with that in the shCtrl group ( $\mathrm{P}=0.014$; Fig. 2C).

Cell proliferation. Following transfection, cell proliferation was evaluated by a Celigo assay for 5 days. Cell proliferation was suppressed from day 3 in the shSTAMBPL1 group (Fig. 3A). An MTT assay revealed that the cell proliferation rates of the shSTAMBPL1 group were significantly decreased compared with those of the shCtrl group on days 3, 4 and 5 $(\mathrm{P}<0.05, \mathrm{P}<0.01$ and $\mathrm{P}<0.001$, respectively; Fig. 3B). Following transfection for 5 days, AGS cell proliferation was evaluated using a clone test. The results of the present study revealed that the AGS clone cell numbers of the shSTAMBPL1 group were significantly decreased compared with those of the shCtrl 
A

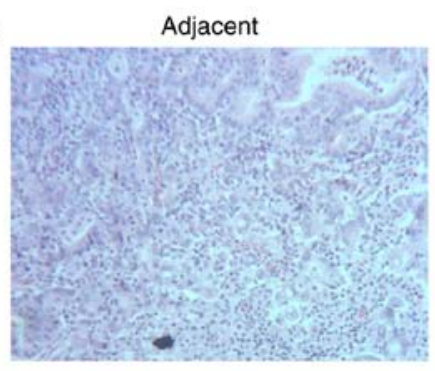

B

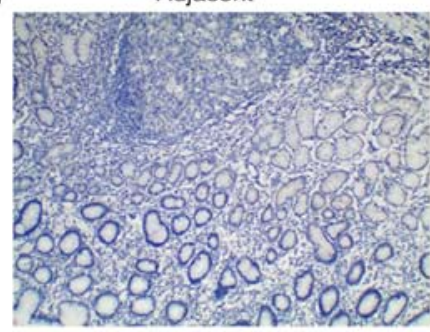

|-I stage

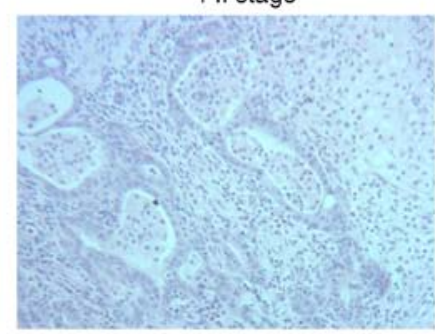

I-II stage

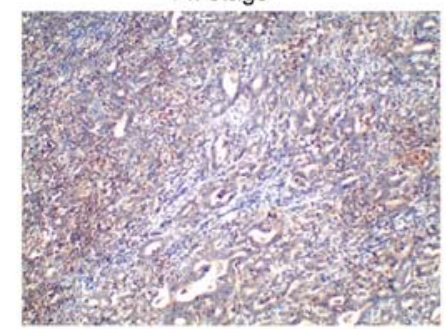

III-IV stage

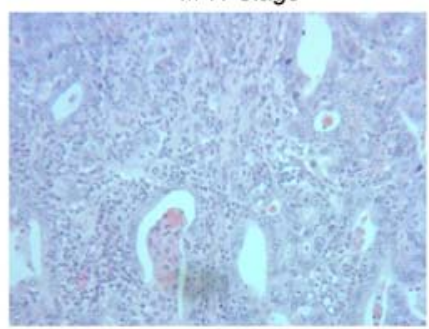

III-IV stage

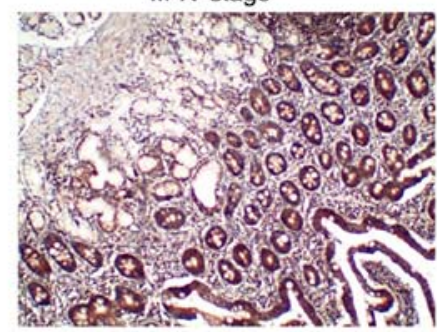

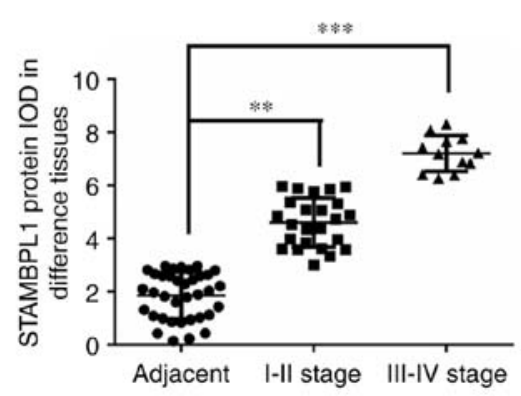

Figure 1. Clinical data and analysis. (A) Pathology of different tissues according to haematoxylin and eosin staining. Magnification x100. (B) STAMBPL1 protein expression of different groups according to immunohistochemical staining. Magnification, $\mathrm{x} 100$. $^{* *} \mathrm{P}<0.01,{ }^{* * * *} \mathrm{P}<0.001$. I-II stage, stages I-II of gastric cancer; III-IV stage, stages III-IV of gastric cancer; adjacent, adjacent normal tissues which did not contain cancer cells; IOD, integral optical density; STAMBPL1, STAM binding protein-like 1.

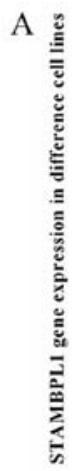
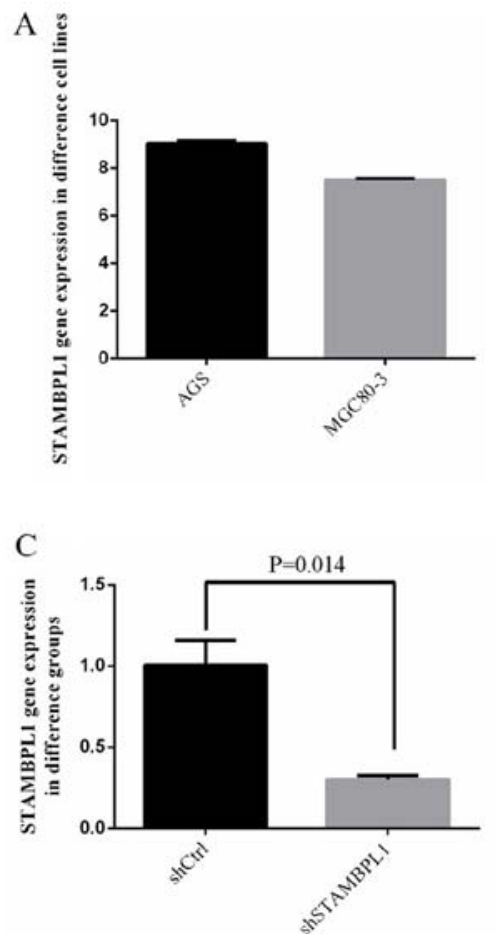

B
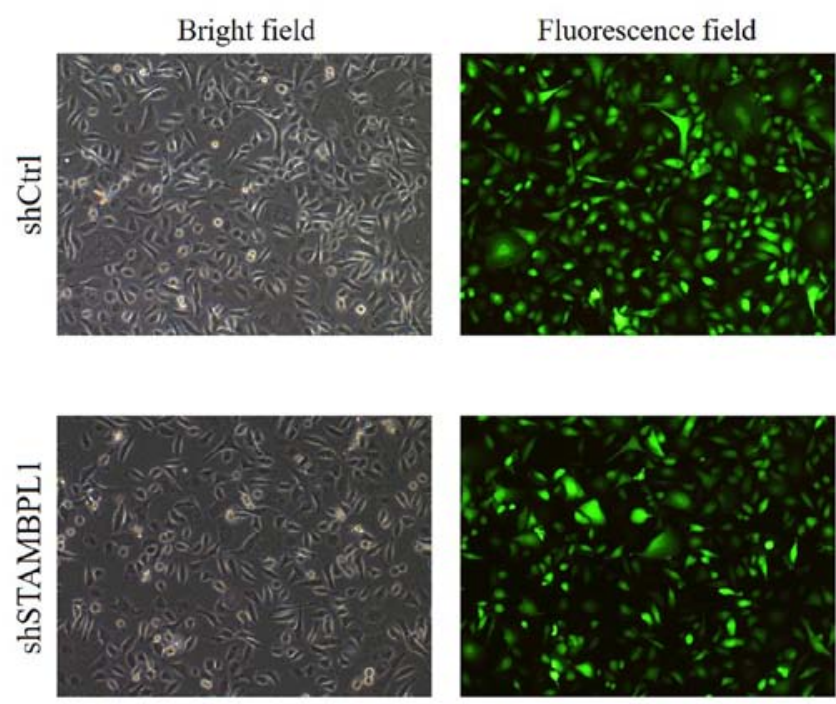

Figure 2. STAMBPL1 expression in different cell lines and transfection. (A) STAMBPL1 gene expression in different gastric cancer cell lines. (B) Transfection of AGS cells with empty vector and shSTAMBPL1. Magnification x100. (C) STAMBPL1 gene expression in different groups. Ctrl, control/empty vector; sh, short hairpin RNA; STAMBPL1, STAM binding protein-like 1. 
A
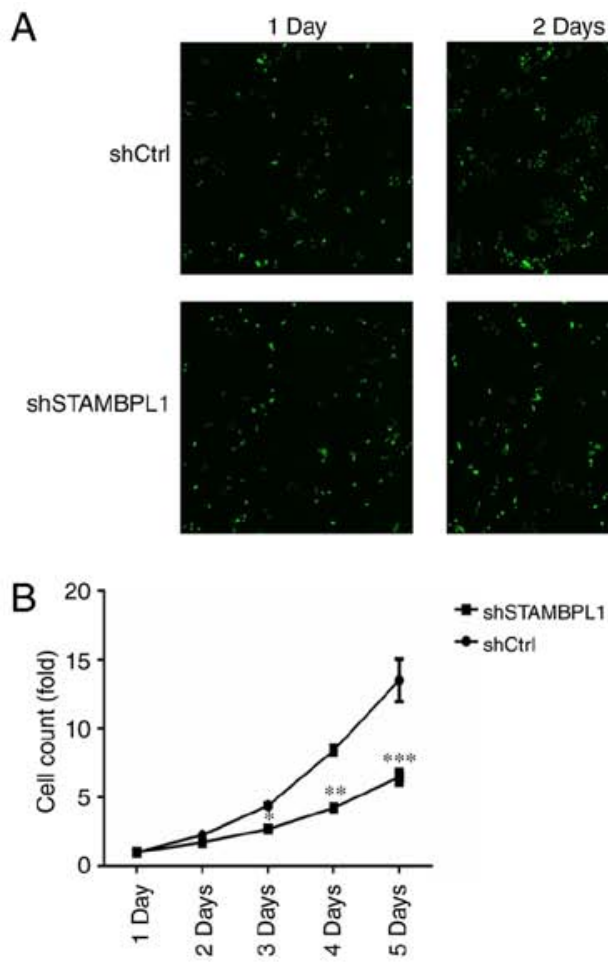

2 Days
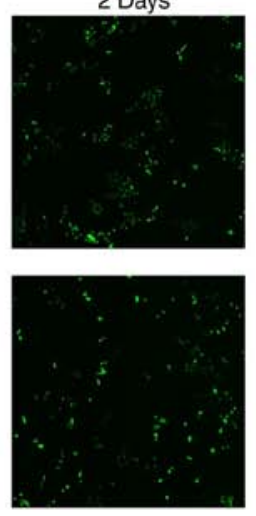

C
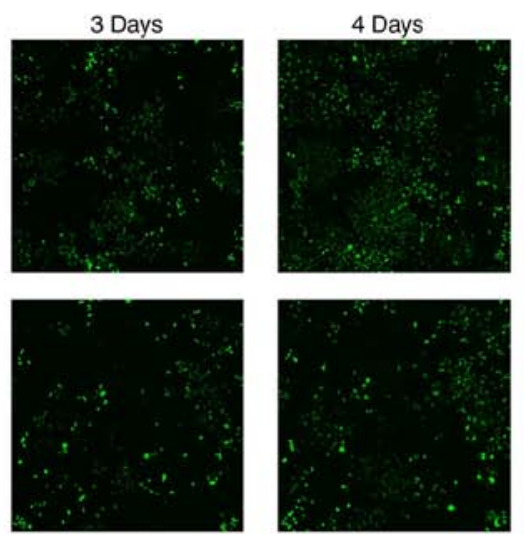

${ }_{\text {shCtrl }}$

ShSTAMBPL1
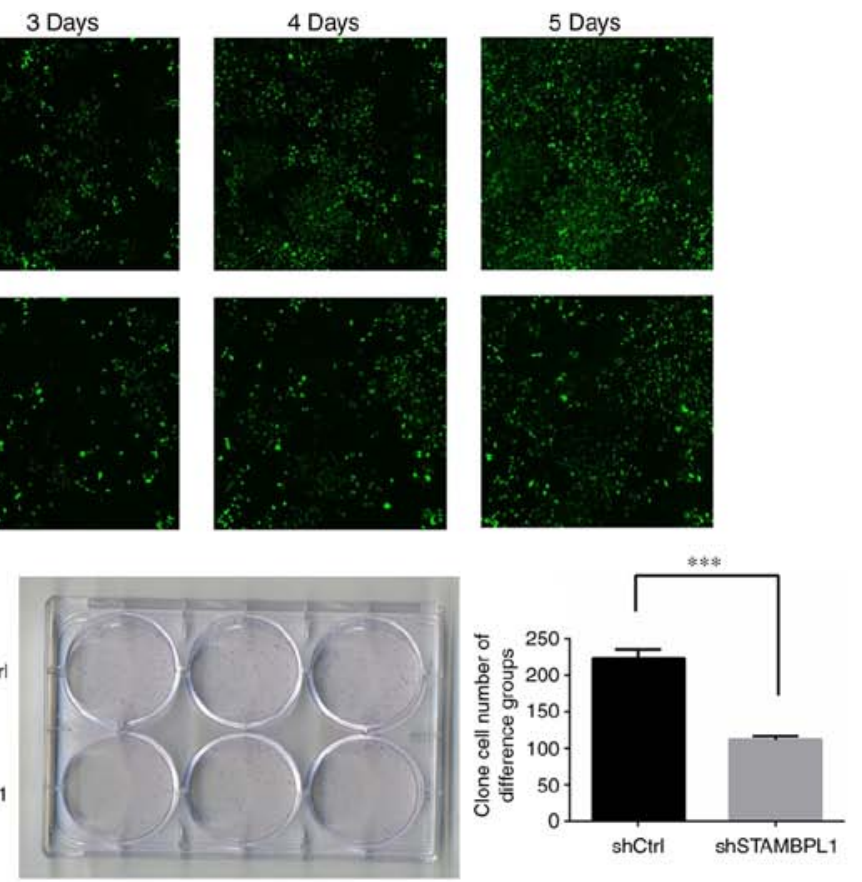

Figure 3. Cell proliferation rates of the shSTAMBPL1 and shCtrl groups. (A) Celigo cell count assay. Magnification x100. (B) Cell proliferation as determined by an MTT assay. (C) Clone formation assay. ${ }^{*} \mathrm{P}<0.05,{ }^{* *} \mathrm{P}<0.01,{ }^{* * *} \mathrm{P}<0.001$ vs. shCtrl group. Ctrl, control/empty vector; sh, short hairpin RNA; STAMBPL1, STAM binding protein-like 1 .
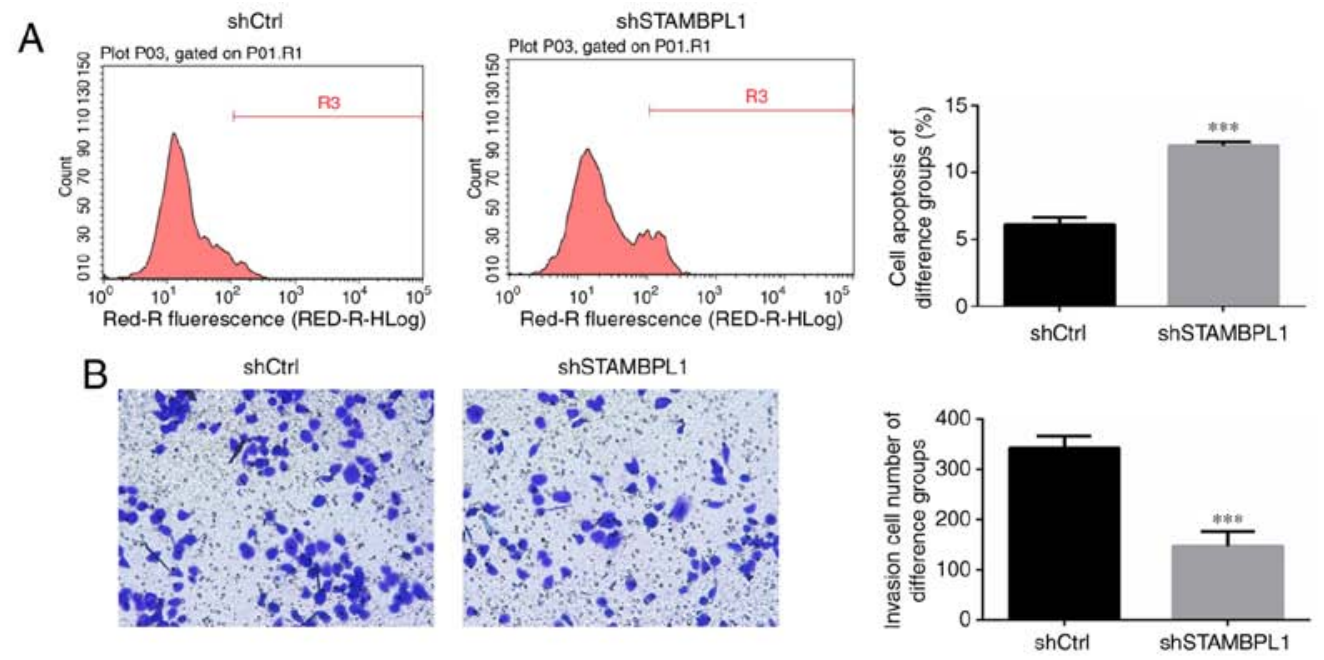

C
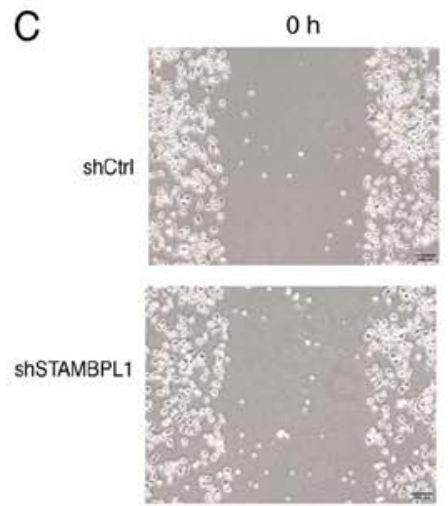

$24 \mathrm{~h}$
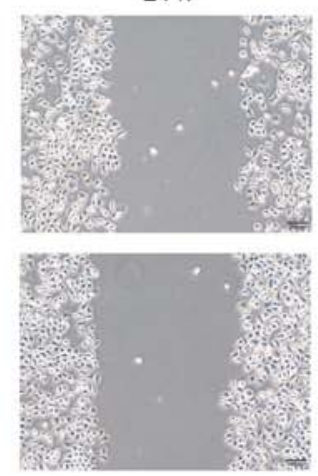
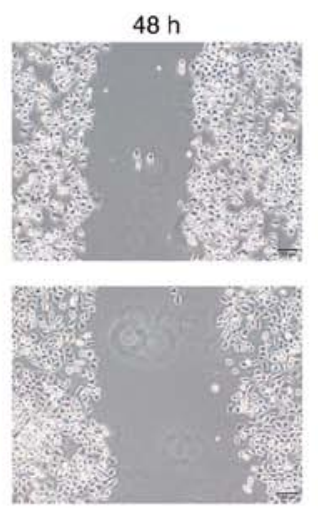

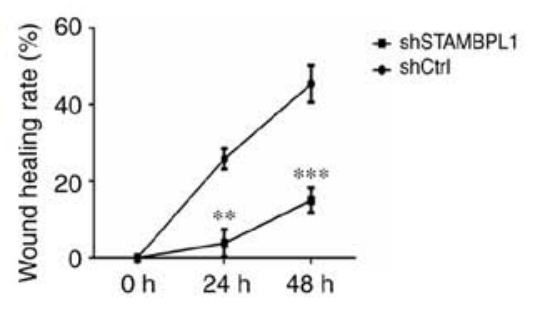

Figure 4. Gastric cancer AGS cell apoptosis, invasion and migration. (A) Cell apoptosis of the shSTAMBPL1 and shCtrl groups. (B) Invasive cell numbers of AGS cells of the shSTAMBPL1 and shCtrl groups. Magnification x200. (C) Wound healing rate of different groups. Scale bar, $100 \mu \mathrm{m}$. ${ }^{* * *} \mathrm{P}<0.01,{ }^{* * * *} \mathrm{P}<0.001$ vs. shCtrl group. Ctrl, control/empty vector; sh, short hairpin RNA; STAMBPL1, STAM binding protein-like 1. 

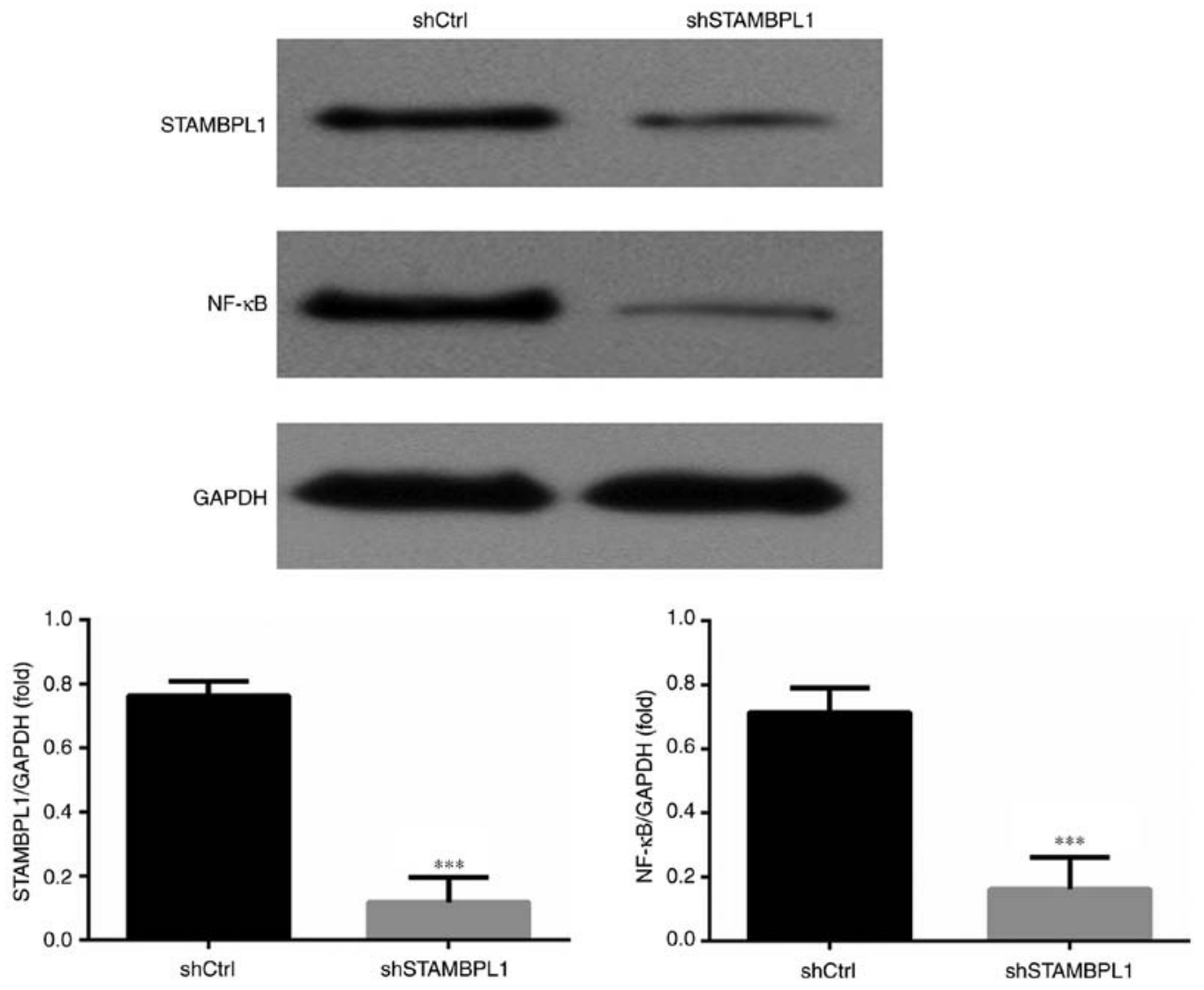

Figure 5. Relative protein expression levels according to western blotting. ${ }^{* * *} \mathrm{P}<0.001$ vs. shCtrl group. Ctrl, control/empty vector; sh, short hairpin RNA; STAMBPL1, STAM binding protein-like 1.

group $(\mathrm{P}<0.001$; Fig. $3 \mathrm{C})$. These results suggested that AGS cell proliferation was suppressed by STAMBPL1 knockdown.

AGS cell apoptosis, invasion and migration. The results of the Annexin V-APC assay revealed that the AGS cell apoptosis rate was significantly increased in the STAMBPL1 knockdown group compared with the shCtrl group $(\mathrm{P}<0.001$; Fig. 4A). AGS cell invasion abilities of the shCtrl and shSTAMBPL1 groups were evaluated using a Transwell assay. The results revealed that numbers of invasive AGS cells in the shSTAMBPL1 group were significantly decreased compared with those in the shCtrl group ( $\mathrm{P}<0.001$; Fig. 4B). To evaluate the AGS cell migration ability, the wound-healing distance in different groups of AGS cells were measured at 0,24 and $48 \mathrm{~h}$ post-transfection. The results revealed that the wound healing rate of the shSTAMBPL1 group was significantly decreased compared with that of the shCtrl group after 24 and $48 \mathrm{~h}$ $(\mathrm{P}<0.01$ and $\mathrm{P}<0.001$, respectively; Fig. 4C).

Relative protein expression levels in the WB assay. Compared with in the shCtrl group, the STAMBPL1 and NF- $\mathrm{KB}$ protein expression levels of the shSTAMBPL1 group were significantly decreased in AGS cells $(\mathrm{P}<0.001$; Fig. 5).

\section{Discussion}

In China, the incidence of gastric cancer is high, and it was the second-most common type of cancer in 2017 (10). The early symptoms of gastric cancer are insignificant. On discovery, it usually presents at its advanced or metastasised stage, when surgical treatment is not ideal. Presently, a combination of surgery and chemotherapy is used for treatment. However, chemotherapy may result in drug resistance, and the drug toxicity is relatively strong (11). Invasion and metastasis occur frequently in patients with advanced gastric cancer, which affects the therapeutic efficiency of gastric cancer. Therefore, the molecular mechanism of the invasion and metastasis of gastric cancer cells is of great significance for the diagnosis and treatment of gastric cancer.

STAMBPL1 is the main factor of the JAMM family members. Additionally, previous studies have reported high expression levels of STAMBPL1 in cancer tissues and that knockdown of STAMBPL1 could suppress the biological activities of leukaemia via regulation of NF- $\kappa B$ activity (12-14). In the present study, it was also demonstrated that STAMBPL1 protein expression was higher in gastric cancer tissues compared with that in adjacent normal tissues and that the expression levels increased with advanced stages in the clinical samples. Furthermore, knockdown of STAMBPL1 by shSTAMBPL1 resulted in STAMBPL1 downregulation, which in turn decreased the cell proliferation of AGS gastric cancer cells, increasing cell apoptosis, cell invasion and migration in vitro. The present study also revealed that NF- $\mathrm{\kappa B}$ expression was decreased following STAMBPL1 knockdown.

Previous studies have indicated that NF- $\kappa \mathrm{B}$ serves an important role in cell proliferation, differentiation and 
apoptosis pathophysiological processes $(15,16)$. Cell migration and invasion serve an important role in the process of cancer metastasis $(17,18) . \mathrm{NF}-\kappa \mathrm{B}$ is a transcription factor with various regulatory functions in the body, and is involved in the differentiation, apoptosis and migration of tumour cells and can promote the development of tumours $(19,20)$. NF- $\kappa \mathrm{B}$ is usually present in the cytoplasm in an inactive manner, and it is activated by phosphorylation following stimulation. The abnormal activation of its pathway can cause the abnormal expression of several tumour suppressor genes, resulting in the inhibition of apoptosis of tumour cells, normal cell differentiation and, notably, NF- $\kappa \mathrm{B}$ overexpression leads to tumour metastasis (21-25). The results of the present study suggested that NF- $\kappa$ B expression was significantly decreased following STAMBPL1 downregulation, which may be associated with the antitumour effects of STAMBPL1 knockdown.

There were some limitations of the present study. Only one gastric cancer cell line (AGS) was extensively analysed in the present study. In future studies, the effects and mechanism of STAMBPL1 on biological activities in two or more gastric cancer cell lines will be assessed.

In conclusion, STAMBPL1 may be an oncogene in gastric cancer, and knockdown of STAMBPL1 affected the regulation of gastric cancer cell biological activities, including the proliferation, apoptosis, invasion and migration via suppression of $\mathrm{NF}-\kappa \mathrm{B}$ signalling in vitro.

\section{Acknowledgements}

Not applicable.

\section{Funding}

The Natural Science Research Project of Education Office of Anhui Province (No. KJ2019A0387)

\section{Availability of data and materials}

The datasets used and/or analysed during the present study are available from the corresponding author on reasonable request.

\section{Authors' contributions}

DJY conceived and designed the study and guaranteed its integrity. JQ participated in the design of the experiment and performed literature research. XJ performed clinical and experimental studies. JL acquired and analysed the data. CXG preformed statistical analysis and prepared the manuscript. XCY designed the study and analysed the data.

\section{Ethics approval and consent to participate}

The present study was approved by the Ethics Committee of The First Affiliated Hospital of Bengbu Medical College. All patients provided written informed consent.

\section{Patient consent for publication}

Not applicable.

\section{Competing interests}

The authors declare that they have no competing interests.

\section{References}

1. Kanda M and Kodera Y: Recent advances in the molecular diagnostics of gastric cancer. World J Gastroenterol 14: 9838-9852, 2015.

2. Chen W, Zheng R, Baade PD, Zhang S, Zeng H, Bray F, Jemal A, Yu XQ and He J: Cancer statistics in China, 2015. CA Cancer J Clin 66: 115-132, 2016.

3. Perrotti D and Neviani P: Protein phosphatase 2A: A target for anticancer therapy. Lancet Oncol 14: e229-e238, 2013.

4. Qu X, Yu J, Bhagat G, Furuya N, Hibshoosh H, Troxel A, Rosen J, Eskelinen EL, Mizushima N, Ohsumi Y, et al: Promotion of tumorigenesis by heterozygous disruption of the Beclin I antorpharge gene. J Clin Invest 112: 1809-1820, 2003.

5. Lavorgna A and Harhaj EW: An RNA interference screen identifies the Deubiquitinase STAMBPL1 as a critical regulator of human T-cell leukemia virus type 1 tax nuclear export and NF- $\kappa$ B activation. J Virol 86: 3357-3369, 2012.

6. Shahriyar SA, Woo SM, Seo SU, Min KJ and Kwon TK: Cepharanthine enhances TRAIL-mediated apoptosis through STAMBPL1-mediated downregulation of survivin expression in renal carcinoma cells. Int J Mol Sci 22: 19, 2018.

7. Berman TA and Schiller JT: Human papillomavirus in cervical cancer and oropharyngeal cancer: One cause, two diseases. Cancer 15: 2219-2229, 2017.

8. Pang L, Wang J, Fan Y, Xu R, Bai Y and Bai L: Correlations of TNM staging and lymph node metastasis of gastric cancer with MRI features and VEGF expression. Cancer Biomark 23: 53-59, 2018.

9. Livak KJ and Schmittgen TD: Analysis of relative gene expression data using real-time quantitative PCR and the 2(-Delta Delta C(T)) method. Methods 25: 402-408, 2001.

10. Ma X, Ren D, Kan J, Zheng F, Zhang S, Zhang Y, Li Y, Liu Z, Ye L, Shen G, et al: Clinicopathological characteristics and prognoses of elderly gastric cancer patients after R0 resection: A multicenter study in china. J Environ Pathol Toxicol Oncol 37: 81-91, 2018

11. Mazzei MA, Bagnacci G, Gentili F, Nigri A, Pelini V, Vindigni C, Mazzei FG, Baiocchi GL, Pittiani F, Morgagni $\mathrm{P}$, et al: Gastric cancer maximum tumour diameter reduction rate at CT examination as a radiological index for predicting histopathological regression after neoadjuvant treatment: A multicentre GIRCG study. Gastroenterol Res Pract 15: 1794524, 2018

12. Lee NH, Kim M, Oh SY, Kim SG, Kwon HC and Hwang TH: Gene expression profiling of hematologic malignant cell lines resistant to oncolytic virus treatment. Oncotarget 3: 1213-1225, 2017.

13. Li CW and Chen BS: Investigating core genetic-and-epigenetic cell cycle networks for stemness and carcinogenic mechanisms, and cancer drug design using big database mining and genome-wide next-generation sequencing data. Cell Cycle 15: 2593-2607, 2016

14. Sacco JJ, Coulson JM, Clague MJ and Urbé S: Emerging roles of deubiquitinases in cancer-associated pathways. IUBMB Life 62: 140-157, 2010.

15. Pahl HL: Activator and target genes of Rel/NF- $\kappa B$ transcription factors. Oncogene 18: 6853, 1999.

16. Karin M: The beginning of the end: IkappaB kinase (IKK) and NF-kappa B activation. J Biol Chem 24: 27339-27342, 1999.

17. Appert-Collin A, Hubert P, Crémel G and Bennasroune A: Role of ErbB receptors in cancer cell migration and invasion. Front Pharmacol 24: 283, 2015.

18. Lauffenburger DA and Horwitz AF: Cell migration: A physically integrated molecular process. Cell 9: 359-369, 1996.

19. Prabhu L, Mundade R, Korc M, Loehrer PJ and Lu T: Critical role of NF- $\kappa B$ in pancreatic cancer. Oncotarget 30: 10969-10975, 2014.

20. Shinoda K, Kuboki S, Shimizu H, Ohtsuka M, Kato A, Yoshitomi H, Furukawa K and Miyazaki M: Pinl facilitates $\mathrm{NF}-\kappa \mathrm{B}$ activation and promotes tumour progression in human hepatocellular carcinoma. Br J Cancer 3: 1323-1331, 2015. 
21. Zhao M, Gao Y, Wang L, Liu S, Han B, Ma L, Ling Y, Mao S and Wang $X$ : Overexpression of integrin-linked kinase promotes lung cancer cell migration and invasion via $\mathrm{NF}-\kappa \mathrm{B}$-mediated upregulation of matrix megalloproteinase-9. Int J Med Sci 14: 995-1002, 2013

22. Woo JH, Park JW, Lee SH, Kim YH, Lee IK, Gabrielson E, Lee SH, Lee HJ, Kho YH, and Kwon TK: Dykellic acid inhibits phorbol myristate acetate-induced matrix metalloproteinase- 9 expression by inhibiting nuclear factor kappa B transcriptional activity. Cancer Res 15: 3430-3434, 2003.

23. Yamamoto Y and Gaynor RB: Ikappa B kinase: Key regulators of the NF-kappa B pathway. Trends Biochem Sci 29: 72-79, 2004.
24. Zhi Y, Duan Y, Zhou X, Yin X, Guan G, Zhang H, Dong Q and Yang K: NF- $\kappa$ B signaling pathway confers neuroblastoma cells migration and invasion ability via the regulation of CXCR4. Med Sci Monit 21: 2746-2752, 2014.

25. Chiu CT, Chen JH, Chou FP and Lin HH: Hibiscus sabdariffa leaf extract inhibits human prostate cancer cell invasion via down-regulation of Akt/NF-kB/MMP-9 pathway. Nutrients 24: 5065-5087, 2015.

This work is licensed under a Creative Commons Attribution-NonCommercial-NoDerivatives 4.0 International (CC BY-NC-ND 4.0) License. 